\title{
TRAYECTOS E IMAGINARIOS URBANOS FINISECULARES EN LA POESÍA DE MUJERES EN EL CONOSUR*
}

\author{
Fernanda Moraga-García**
}

\section{Resumen}

Este artículo sitúa al centro de su discusión la pregunta: ¿qué ciudad -o ciudades- son aquellas sobre las que las producciones poéticas de mujeres en el Conosur americano privilegian durante los dos últimos decenios del siglo XX? Sin duda, es imposible dar respuestas exhaustivas a esta interrogante en un espacio escritural delimitado como este. Por lo tanto, se trata aquí de realizar una breve relación descriptiva que -por ahora- dé cuenta de un trayecto cartográfico alrededor de diferentes representaciones del espacio especialmente urbano, en la poesía de mujeres conosureñas durante las dictaduras de los 80 y el periodo que abarca las primeras postdictaduras de la década de los 90 .

Palabras clave: poesía, Conosur, dictadura, postdictadura, ciudad.

\section{JOUENEYS AND FINISECULAR URBAN IMAGINARIES IN THE POETRY OF WOMEN IN THE SOUTHERN CONE}

\begin{abstract}
This article focusesin the question: which city - or cities - are those that privilege the poetic productions of women in the American Southern Cone during the last two decades of the 20th century? Without a doubt, it is impossible to give comprehensive answers to this matter in a scriptural defined space like this. Therefore, we are going to make here a brief descriptive exploration that - for now - realizes a cartographic journey around different representations especially of urban space, in the poetry of conosureñas women during the dictatorships of the $80 \mathrm{~s}$ and the period covered by the first postdictatorship of the 90 's.
\end{abstract}

Keywords: poetry, Southern Cone, dictatorship, postdictatorship, city.

Recibido: 28-10-2015

Aceptado: 26-01-2016

* $\quad$ Este trabajo es parte de mi Proyecto FONDECYT Postdoctoral 2014 N 3140316, titulado: “Memoria, ciudad y subjetividad en la poesía de mujeres del Conosur (1980-2000)".

* Chilena. Doctora en Literatura Chilena e Hispanoamericana de la Universidad de Chile. Investigadora del Centro de Estudios Avanzados (CEA), Universidad de Playa Ancha, Valparaíso, Chile. fernanda.moraga@upla.cl 
...estamos fuera, irremisiblemente fuera de las cosas que hace la ciudad, y desde esa exclusión inventamos un contacto y una permanencia y un conocimiento con la secreta admirable desesperación con que lo hemos inventado todo.

Julio Cortázar

El Gran Kan posee un atlas en el cual están reunidos los mapas de todas la ciudades: las que levantan sus murallas sobre los firmes cimientos, las que cayeron en ruinas y fueron tragadas por la arena, las que existirán un día y en cuyo lugar sólo se abren por ahora las madrigueras de las liebres [...] El atlas tiene esta virtud: revela la forma de las ciudades que todavía no poseen forma ni nombre.

Ítalo Calvino

\section{Alrededor de la ciudad latinoamericana}

En América Latina, históricamente ha habido un énfasis en el control del espacio. Como ya conocemos, las empresas de conquista y luego de colonización estuvieron dadas, entre otras cosas, casi fundamentalmente porque el espacio americano fue concebido -imaginado- como tábula rasa. Los pueblos indígenas fueron considerados sin historia, por lo tanto, pasaron a formar parte de un mapa, de un ordenamiento cartográfico occidental que proponía -imponía- la separación entre tiempo y espacio. Entonces, el tiempo en -de- América no fue visualizado ni espacializado y, menos, materializada su propia historia indígena. De esta forma, el ordenamiento urbano de América correspondió a una imaginación y a un imaginario Occidental que establecía un espacio cuadriculado en dameros que funcionó como mecanismo de control y superposición de poderes a partir de los cuales se producía,por primera vez, la marginalización del continente americano respecto de un centro metropolitano europeo ${ }^{1}$. Sin

1 "Es importante destacar la trascendencia que tuvo la coincidencia de la Conquista de América con los nuevos descubrimientos científicos que tuvieron lugar dándose impulso mutuamente. Por ejemplo: paralelamente a la fundación vertiginosa de ciudades (ordenadas, cuadriculadas), se habían inventado las líneas de latitud que continuaban la organización matemática de lo urbano a nivel mundial, dividiendo el mundo en secciones (Norte/Sur; Este/Oeste). A pesar de que el problema de medir la longitud no se resolvería hasta mucho más tarde (Sobel), el famoso Atlas que Mercator diseñó entre 1538 y 1595 indica que los mares se habían vuelto navegables. Reinscribe el espacio con nombres europeos que erradicaron nombres indígenas $\mathrm{y}$, como otros mapas, trata de borrar el conocimiento indígena del espacio para crear un espacio imaginado por Occidente como un ente objetivo que podía ser conocido y controlado desde un punto de vista superior y exterior a él". Silvia Spitta. "Prefacio. Más allá de la ciudad letrada", p. 9. 
embargo, bajo este control de urbanización colonial coexisten relaciones entre espacio y tiempo construidas por las sociedades indígenas, las que entrarían en interacción conflictiva con el formato urbano colonial. A esta interacción, Mignolo la denomina "semiosis colonial", es decir, se trata de un complejo sistema cultural donde entran en juego diferentes signos y en el cual quedan a la vista "las fracturas, las fronteras, y los silencios que caracterizan las acciones comunicativas y las representaciones en situaciones coloniales" (Migno los/p). La ciudad, así concebida, funciona como una especie de fortificación y representación de la "civilización" respecto de la "barbarie" que quedaba fuera de ella y con la que entra en tensión. Por lo tanto, la configuración urbana en América Latina se formó a partir de placas telúricas, sociales, políticas y culturales en pugna: las ciudades indígenas sumergidas -no sin resistencia-, bajo las ciudades letradas impuestas por occidente: "la ciudad letrada se amuralla y, en su afán por controlar los signos, parece crear un vacío por donde se filtra el desorden que va a ser la característica fundamental de nuestras ciudades. (Rama en Spitta13).

De este modo, la ciudad latinoamericana se ha construido como espacio complejo y heterogéneo que, históricamente hasta hoy, emerge como una producción topográfica variable en donde se diseñan y habitan realidades diversas dentro de un arco marcado por una parte, por la cartografía cuadrada del damero colonial y por otra, por el desasosiego y la desertificación avasalladores que se experimentan en las mega ciudades actuales $^{2}$. Entonces, y para entrar al tema que convoca a este artículo, nos preguntamos, primero, por la función de la poesía como género de representación y ficcionalización -imaginación- de la realidad en cuanto depositaria y productora de sentidos y signos espaciales. Y segundo, y quizás esta sea la interrogante que se sitúa al centro de este estudio: ¿qué ciudad -o ciudades- son aquellas sobre las que las producciones poéticas de mujeres en el Conosur americano enfatizan durante los dos últimos decenios del siglo XX?Sin duda, es imposible dar respuestas exhaustivas

2 A esto hay que agregar que el ordenamiento urbano, diseñado por los sistemas de dominio para disciplinar y controlar los trayectos de las personas, inevitablemente se "contamina" de múltiples itinerarios y trayectorias que dejan entrever un sinnúmero de niveles urbanos que cohabitan de manera compleja. Esto tiene que ver con la representación material de una multiplicidad de niveles sociales, culturales y raciales entre otros, que componen la realidad latinoamericana. Por lo mismo, la ciudad como espacio de interacción de subjetividades individuales y colectivas debe ser comprendida como un complejo tejido en el que ciertas condiciones materiales y de elaboración simbólica se vinculan de maneras particulares y muchas veces en tensión y que además, intervienen en una variedad de campos de poder y de acción social. 
en un espacio escritural delimitado como del que dispongo en estos momentos. Sin embargo, me parece que para la primera interrogante,ya Lucía Puppo nos acerca a una certera respuesta al decir que:

La poesía explora los límites difusos de la cercanía y la distancia, el todo y la parte, la confianza y la sospecha, la pertenencia y la pérdida. [Entonces], la pregunta por el espacio en la poesía no tiene que ver con un afán métrico, mimético o totalizador, sino con el acto de restituir una experiencia, de devolverle al espacio su contexto vital, simbólico y afectivo. [...].

Todo poema evoca un espacio, referencial o imaginario, a partir de la enunciación de un sujeto y de su peculiar focalización o punto de vista. (11)

Respecto de la segunda pregunta que nos hacemos, me propongo realizar, más que un trabajo de interpretación y análisis, una breve relación descriptiva que -por ahora- dé cuenta de un trayecto cartográfico alrededor de diferente representaciones del espacio, especialmente urbano, en la poesía de mujeres conosureñas durante las dictaduras de los 80 y el periodo que abarca las primeras postdictaduras en la década de los 90 .

Podemos decir que la producción poética a la que aludimos propone diferentes tejidos y gradaciones de la ciudad contemporánea, principalmente de los bordes urbanos, más allá o en los extramuros de los centros históricos y de los espacios oficiales. Esto quiere decir que en esta poesía finisecular de mujeres, hallamos un trayecto urbano que podría tener sus huellas y sus memorias en aquellas organizaciones sociales y cívicas preeuropeas a las que nos referíamos más arriba: las ciudades hundidas y excluidas -bajo y fuera- de las murallas occidentales. Decimos esto porque de manera próxima, tanto a la conformación del campo poético de las mujeres conosureñas a fines del siglo XX, como del imaginario urbano que aparece en sus textos; la organización espacial de los pueblos precolombinos es una inscripción que aún tiene lugar -el que no se vea o el que esté censurado y racializado por los discursos de dominio, no quiere decir que no exista-. Esto significa que, por un lado, la ciudad indígena se transforma en huella de memoria y por otro lado, al tener lugar, también tiene una "localización geo-gráfica" (Déotte, 2013). 
En este sentido, podemos encontrar varios caminos de cruce en los que no ahondaré por ahora.Aquí solo quisiera dar un ejemplo: la mayor parte de los espacios -sino casi todos- de organización política precolombinos con sus continuidades y cortes en el tiempo hasta hoy ${ }^{3}$, así como la mayor parte del campo escritural de las mujeres, han quedado por demasiado tiempo fuera del contrato temporal y espacial oficial. Esto implica que los imaginarios urbanos en la poesía contemporánea de mujeres -indígenas y no indígenas-, se construyan a partir de los fragmentos de una periferia urbana, ya que, en ambos casos, existe -con matices de raza, clase y género-, una devaluación de la experiencia y el conocimiento ${ }^{4}$.

Entonces, la poesía que nos ocupa en estos momentos produce localizaciones urbanas particulares y subterráneas, más que ciudades completas -que por lo demás, son inabarcables-. Se trata de fracciones urbanas que se elaboran a partir de los fragmentos y las señales que dejan la experiencia del vivenciar y del resistir la violencia militar y su herencia por una parte, y el estado de excepción de un neoliberalismo que se afianza a partir del primer proceso de postdictaduras en el Conosur, por otra ${ }^{5}$. Hablamos de imaginarios urbanos que se van conformando en el acto mismo de apropiación de determinados lugares que se articulan a memorias parciales, afectividades y también a sentidos compartidos por una comunidad o sociedad marginal. Se trata de una ciudad que va más allá de las grandes construcciones -relatos- urbanas de la megápolis. Por lo mismo, sus protagonistas suelen ser, al mismo tiempo, sujetos comunes y singulares que se apropian de parcialidades urbanas de forma diferencial, buscando posibles arraigos en memorias locales. De este modo, las autoras pueblan las calles, las poblaciones, los pasajes, incluso las avenidas centrales con recorridos urbanos periféricos, con relatos de género, de margen, de silencios, de resistencias, etc. Incluso, hay trayectorias citadinas que no aparecen o que deliberadamente se

3 Es necesario recordar que las construcciones espaciales, tanto materiales como simbólicas, no pueden comprenderse fuera de lo temporal.

$4 \mathrm{Al}$ respecto revisar Lucía Guerra. La ciudad ajena. Subjetividades de origen mapuche en el espacio urbano. Santiago de Chile: Ceibo Ediciones, 2014.

5 La configuración urbana en la poesía de mujeres dentro del Conosur no tiene una producción homogénea ni menos coordinada a modo de "una" construcción que responde en bloque a los contextos de los cuales se originan. A través del desarrollo de esta investigación, pude observar que la ciudad como discurso material y simbólico dentro de los textos revisados tiene una mayor proliferación dentro de las propuestas de las poetas chilenas. En Uruguay existe una tendencia que se encamina hacia los espacios de la naturaleza, mientras que en Argentina predominan los espacios privados como la casa o sus sinécdoques, la ventana, la puerta y el living, entre otros. 
silencian,a modo de simbolizar los cuerpos desparecidos y muertos, como es en el caso de los contextos de dictaduras.

Esta producción poética de mujeres conosureñas recupera la noción de ciudad como ese espacio espeso en experiencias, memorias y significados que originan sentidos de complejidad, de diversidad y de alteridad. La mayor parte de las autoras, insiste en traer al centro de la experiencia la idea de la ciudad como espacio privado, es decir, el sujeto con su propia experiencia en la calle. Así, lo público se hace privado o en el decir de Benjamin (1996),el espacio se hace "poroso", puesto que un sujeto puede entrar y salir de lo privado a lo público y viceversa dentro del escenario de la representación teatral. En este caso, lo extrapolamos a la representación poética:

$\mathrm{Al}$ anochecer

muchas casas tienen todavía las puertas entre abiertas:

franjas de luz, cruzando las baldosas

llegan hasta la calle.

Durante todo el día

van $\mathrm{y}$ vienen personas

que no cierran las puertas

sino que las entornan...

Quedan a veces

a la vista una planta, un zaguán, escalones.

Y el misterio se instala a plena luz

porque ahora

cada puerta entornada ha dejado volarse

un hálito

de la cerrada vida de la casa. 
(Las hojas de la planta del zaguán se agitan

débilmente

por el viento que llega de la calle) (Maia 350) ${ }^{6}$

Se trata de parcialidades o rendijas urbanas, las que son producto de subjetividades singulares que surgen comouna suerte de "arqueología simbólica" (Makowski, 2007). Y en este punto me gustaría detenerme un momento para retornar una afirmación de Benjamin, la que hace mucho sentido a nuestra relación. Me refiero a la ya citada articulación entre espacio y tiempo. Para el autor, la memoria es fundamental en la reconstrucción y perspectiva que el sujeto tiene de los espacios:

Quien ha empezado a abrir el abanico de los recuerdos encuentra siempre nuevas piezas, nuevas varillas. Ninguna imagen le satisface porque ha comprendido que, al desplegarse, lo esencial se presenta en cada uno de los pliegues: cada imagen, cada sabor, cada sensación táctil por las que hemos abierto todo esto se han desdoblado a su vez, y ahora el recuerdo va de lo pequeño, de lo más pequeño, a lo microscópico; lo más grandioso se halla siempre en lo que aún está por descubrirse en este microcosmos. (Benjamin en Déotte 136).

En esta perspectiva, el hallazgo voluntario de restos espaciales y temporales que hacen las poetas en sus textos funciona a modo de una "arqueología", en cuanto se adentran en un abanico de excavaciones urbanas para restablecer posibles identidades de contravención que actúan a partir de microbiografías políticas. Es así que la poesía de mujeres a la que nos referimos produce espacios públicos de lo privado, los que en su mayoría emergen de una, también, "arqueología de la memoria". Es debido a esta última que el espacio se transforma en "microcosmos" temporal, alimentado por los diferentes rastros encontrados en las excavaciones o exhumaciones de memorias del subsuelo. Tanto la ciudad parcial, como la memoria privada, configuran una cadena de sentidos políticos que van dando cuenta de diferentes marginalidades y revueltas

6 Este poema llamado "Calle lateral" pertenece al libro De lo visible. Montevideo: Siete Poetas Hispanoamericanas, 1998. 
de la subjetividad y la experiencia, teniendo como consecuencia la construcción de un territorio por donde hacer transitar estas huellas, las que básicamente corresponden a políticas de la memoria y del espacio.

Es a partir de estas breves reflexiones que me interesa precisar que, a lo menos, podrían existir tres imágenes inmediatas de la ciudad en el campo poético de mujeres en el Conosur durante las últimas dos décadas del siglo recién pasado. Se trata de representaciones urbanas no aisladas o definidas, en donde la diferenciación obedece a una propuesta de lectura de exploración aproximativa, sin la pretensión de una desfavorable sistematización.

\section{Ciudad pánico}

Esta ciudad del pánico ${ }^{7}$ que proponemos aquí, fundamentalmente, se materializa en la escritura hacia fines de los años setenta y durante los ochenta, momento en que el Conosur se encontraba cercado por las dictaduras, las que hacían del terror su política de Estado. A partir de la sistematización e institucionalización de la tortura, la desaparición forzada y el asesinato como dispositivos de disciplinamiento social, se reorganizó también el espacio urbano. La ciudad como una trama compleja de flujos culturales, políticos y sociales sufre un repentino corte que se asemeja al corte inicial del cual nacen la mayoría, por no decir todas, las ciudades capitales en América Latina: la superposición violenta de la ciudad occidental sobre la organización social y política de los pueblos indígenas y a lo cual ya nos referimos escuetamente en la introducción a este artículo. Se inaugura así la ciudad sitiada que da origen a una explícita crisis en la experiencia del sujeto, puesto que los relatos que lo sustentaban han sido intervenidos. La nueva ciudad impuesta forma parte de los diversos mecanismos de control usados por los militares, entre ellos el impulso desaforado de un modelo económico basado en el libre mercado, produciendo sujetos anónimos,silenciados, consumidos y mercantilizados que circulan por las calles, imposibilitados de dejar huellas: "esta ciudad sombría ..., esta ciudad es inalterable, esta ciudad quisiese ser rubia, esta ciudad quisiese beber whisky cuando

7 Paul Virilo ha reflexionado sobre el concepto de "ciudad pánico" en el sentido de las ciudades o "metaciudades" actuales, en las cuales la velocidad de la información lleva, por una parte, a la transformación violenta de las relaciones entre espacio y tiempo y, por otra, a la reclusión de estas ciudades en la velocidad "bélica" de la inmediatez de la información. Ver Virilo, Paul. Ciudad pánico. El afuera comienza aquí. Caracas: Monte Ávila Editores Latinoamericanos, 2008. 
se muere de hambre" (Urriola29); ; "se limpian el culo con la mano/y la mano en la pared. / los chicos patean botellas de coca-cola/ o de jugo de mocoretá. / patean desde que llegan hasta que se van." (Poetas argentinas...132) ${ }^{9}$. Es así como lo privado se separa de lo público y se da lugar a la experiencia del trauma y a la fractura del pegamento social. A partir de una estética del trauma, la ciudad emerge como espacio en ruina, puesto que se han desmoronado los trayectos de sentido democrático y colectivo, sobreviniendo el territorio como irreconocible. Además, sobre la fragilización del espacio no subsiste más que la resistencia, el silencio y la degradación; por lo tanto, el acontecimiento de la singularidad desaparece y, con ello, deviene la pérdida del tener un lugar en el espacio temporal y por ende, ocupar ese lugar en el espacio material. En este sentido, es el mismo espacio urbano el que está en situación de shock, anulado en su sentido deconceder algún lugar:

Carente de decencia, marginal, fantoche

Patipelá, espingarda ciudad.

Se nos muere la loca

Con una estocada en el lado izquierdo

De su rostro oculto.

Pobre dama, empielada ramera

Transpirando polen

La noche escuálida te dobla

Donde duerme el cafiche. (Berenguer17)

La ciudad se transforma en una zona desolada, pero a la vez colmada de mandatos patriarco-militares y económicos, de cuerpos-objetos, de crímenes -sin cadáveres- y de desapariciones políticas. Por consiguiente, se convierte en ciudad-mercancía y silenciada. En este sentido, el relato se hace insostenible, porque al haber una crisis de la experiencia se produce el quiebre en el lenguaje que dificulta la estructuración de una narración.

8 Este fragmento pertenece al libro Hija de perra, publicado originalmente en 1998 por Cuarto Propio. Aquí se utiliza la segunda edición realizada por Surada Ediciones, en 2002.

9 Esta cita corresponde al poema "Visita" que la autora escribió hacia fines de los 90. Posteriormente, en 2002, fue incluido en la antología Taquigrafía para principiantes, coordinada por Arturo Carrera, Diana Bellessi y Teresa Arijón y editada en Buenos Aires por Ediciones Paradiso. Para este artículo, el poema fue recogido de la antología Poetas argentinas (1961-1980), citada más arriba. 
Esta es una de las razones por las que el lenguaje que utilizan algunas poetas de los 80 -y también algunos poetas-, sea enmascarado, complejo y muchas veces incomprensible a una primera lectura. Otra razón de primer orden, en esta perspectiva, es el ocultamiento del mensaje ante tamaña bota de represión:

esa manera de

estar / colgado así de esa

manera de pies arduos y secos

$[\ldots]$

árboles o azulejos daigual

cemento

piedra en el cuello o cal

tragada viva

estar así de pies / y manos

$[\ldots]$

atento al transcurrir que de costado duele menos

esa posición de pies en vilo / fuera / de sí

no al aire / jadeo hueco / sal en boca / mojada.(Lukin 6) ${ }^{10}$

La ciudad, hasta antes de las dictaduras, se construía como "memoria con forma" -con contenidos y sentidos sociales y políticos-, siendo esto lo que justamente intenta hacer desaparecer la concepción militar y luego neoliberal del espacio. Sin embargo, la poesía como territorio de imaginación estética y de enunciación política -al igual que otros discursos culturales-, le devuelve a la ciudad su contenido y su forma, imaginándola como espacio político en cuanto reivindica subjetividades y se plantea como espacio de experiencias en resistencia a partir de un discurso que no abandona la factura estética.

10 Como se indica en la referencia, este libro fue publicado en 1986. Sin embargo, la autora indica, en el mismo poemario, que éste fue escrito entre los años 1980 y 1982, en plena dictadura argentina. 


\section{Ciudad imaginada}

La propuesta de ciudad imaginada corresponde a aquella que va conformando lugares a partir de los espacios vacíos que ha dejado la dictadura y que en los 90 se horadan aún más con la visión mercantilista del orden urbano. Son los espacios marginales, las territorialidades degradadas que poco a poco son resignificadas por narrativas de género $\mathrm{y}$ de filiaciones cortadas y desde las cuales se inscriben subjetividades parcialmente colectivas, pero que siguen siendo privadas. Se imaginan, entonces, espacios donde se van construyendo las memorias locales y las posiciones singulares del habitar. Son lugares planeados a partir de ciertas políticas de la memoria y del afecto y que, pese a que se trata de configuraciones espaciales que dejan reducidas posibilidades a las experiencias de los sujetos, no ocultan las apropiaciones y la formas particulares de experienciar esos territorios. Lucía Guerra escribe al respecto:

Aquel que vive la ciudad, simultáneamente la inventa, la redice y contradice desde su propia subjetividad. Su percepción y su experiencia, insertas en un contexto corporal, social y cultural, crean así fracturas y remodelizaciones del espacio urbano dando paso a la imaginación, a otros signos, imágenes y narrativas que configuran otra topología simbólica, ajena a los nítidos trazos de cartografías e imaginarios hegemónicos. (Ciudad, género e imaginarios...25)

Esta ciudad de la imaginación lejos está de posicionarse como un espacio utópico donde el restablecimiento de un orden privado y periférico se asemeje a postales de un edén marginal inexistente. Por el contrario, si de postales se trata, Tamara Kamenszain en uno de sus poemas dice:

Odio Buenos Aires.

Su luz mortecina magnífica

$[\ldots]$ 
Quede como odio
toda intención de decir
"mi ciudad"
en el condensado muerto de su luz

yo ya no escribo

ni me seduce

pobrecita de sus barrios

deambulo sin ningún tiempo de sentimiento

$[\ldots]$

Mejor me duermo

con la estampita en la mano

una postal la tengo en la cabeza

toda iluminada

arrugo el obelisco al fondo

y rezo para mí por vos

mi Buenos Aires.

Querido. (Una antología de la poesía argentina...125-126) ${ }^{11}$

Se trata de fragmentos urbanos que se materializan en los textos y que tienen sus anclas en la reivindicación de espacios temporales de la experiencia y no en la nostalgia de un lugar anterior perdido. La imaginación, en esta perspectiva, no corresponde a una fantasía vaciada de sentido político. Por el contrario, son poéticas que proponen un diálogo problematizado con lo imaginado -aquello que se trae de la experiencia al presente-. Es indudable, entonces, que la imaginación a la que aquí aludimos es una construcción articulada a los espacios temporales de la memoria. Son textos que exploran la referencialidad de las imágenes de la experiencia y la problemática a la que están expuestas estas imágenes en manos de la representación oficial y, también, de la inestabilidad del

11 El fragmento citado corresponde al libro Tango bar editado en Barcelona por Sudamericana, en 1998. En este caso se toma de Jorge Fondebrider. Una antología de la poesía argentina(1970-2008). Santiago de Chile: Lom Ediciones, 2008. 
recuerdo. Se suma a esto la consideración del carácter de "verosimilitud" y de ficción de aquellas posiciones enunciativas de la imaginación poética. En otras palabras, la producción poética de mujeres, en esta perspectiva, demanda un discurso crítico respecto de que aquello que no se ve, no porque no esté o no exista más, sino porque se ha institucionalizado y, en este sentido, ha desaparecido porque se ha disciplinado. Ejemplo de esto es el ocultamiento de la degradación del cuerpo en una ciudad sitiada por los poderes:

La Bandera de Chile está tendida entre 2 edificios

se infla su tela como una barriga ulcerada - cae como teta viejacomo una carpa de circo

con las piernas al aire tiene una rajita el medio

una chuchita para el aire

un hoyito para las cenizas del general O'Higgins

un ojo para la Avenida general Bulnes. (Hernández18)

Entonces, la acción de volver a imaginar para hacer presente algún margen absorbido por los discursos dominantes es un acto de revuelta política -en palabras de Kristeva-, porque lo importante es la visibilización de diversas y singulares complejidades de subjetivación en el espacio y el tiempo para, así, tener y ocupar un lugar como sujetos de una realidad histórica.

En estas ciudades imaginadas por las poetas, tiene lugar la creación de estrategias subversivas de sobrevivencia de sujetos expuestos a contextos de violencia y exclusión -ya sea de clase, de género, de raza y, muchas veces, de todas al mismo tiempo-. Se presentan relatos y trayectorias de vida que se problematizan en el eje de esta sobrevivencia, la que se sustenta principalmente en la reconstrucción de experiencias cortadas y en la apropiación de lugares fragmentarios que se reconstruyen desde esa misma experiencia límite. A partir de esta complejización en las enunciaciones, más la condición de sujetos cotidianos de las hablantes, se van trazando procesos identitarios en crisis:

En la ciudad en ruinas ve el viajero un palacio de jade verde: es un museo 
polvoriento, de inscripciones borrosas.

Los libros, como trapos, ya no pueden leerse.

Ese es nuestro futuro... (Maia 252)

\author{
Montones de puertas montones montones \\ montones de casas de remate \\ montones de silencios en tachos de basura \\ montones de caricias en latas de comida
}

(Guerra, el velo magistral... 303) $^{12}$

La imaginación de estas ciudades del fragmento crea territorialidades que se esculpen en la clandestinidad de la aridez de los espacios. De esas periferias, producto de una ciudad que fue vaciada de sus sentidos por las dictaduras militares y luego llenada en las primeras postdictaduras de los 90, con los signos de una economía del consumismo-como ya se ha dicho más arriba-, van apareciendo tejidos urbanos locales, incipientes espacios públicos que se derivan siempre de lo privado y que se transforman en tejidos de comunicación-incomunicación en los que se arraigan formas de afectividad y desafectividad.

\title{
Ciudad de memorias locales
}

No podemos pensar ninguna de las dos ciudades anteriores fuera de la que ahora presentamos. Sin embargo, la ciudad de la imaginación como espacio de producción y reconstrucción de memorias singulares es contenida por la creación de lugares urbanos que recuperan trazos del pasado a partir de un presente complejo y diverso ${ }^{13}$. La ciudad de memorias locales mantiene ciertas diferencias con la ciudad en pánico,

12 Este fragmento corresponde al poema "Casas vacías" que se encuentra en el libro El pan de cada día, publicado en 1975 en Montevideo, bajo el sello de las ediciones Siete Poetas Hispanoamericanas. Aquí se recoge del volumen compilatorio el velo magistral que esconde todo. nancy bacelo [sic], realizado por Silvia Guerra y publicado en 2011.

13 Es importante mencionar que, durante los años 80, también se dieron otras producciones poéticas de mujeres, por ejemplo, aquellas en que había un retorno a un estado primigenio del sujeto mujer, el que tenía que ver con un lugar pre-simbólico materno unido a pulsiones del inconsciente y de la naturaleza. Algunos ejemplos de teóricas y teóricos en los que se apoyó la crítica feminista de la época, e incluso las mismas poetas, fueron: Lucy Irigaray, Julia Kristeva, Sigmund Freud, Jaques Lacan, entre otros y otras. Y en relación a algunas poetas que trabajaron la temática se encuentran: Eugenia Brito en Chile, Marosa di Giorgio en Uruguay y Diana Bellessi en Argentina, solo por mencionar algunas. 
puesto que la construcción de memoria que en esta última predomina, corresponde más al relato de experiencias inmediatas al contexto de violencia que a una estructuración política del pasado. Ambas, la ciudad de la memoria local y de la imaginación,se establecen a partir de la producción de la memoria como espacio político que posibilita subversiones de la identidad en la medida que los influjos de la violencia, de la intervención del tiempo de la economía capitalista en todos los aspectos de la vida humana y de la patriarcalidad de los sistemas de dominio han atropellado lugares, historias, memorias y sujetos:

Cuando este cuerpo está renunciando sobreviene una leve, insostenible mejoría, una mejoría que será arrastrada por una nueva enfermedad, este cuerpo me abandona, constantemente me está abandonando, se duerme, cuando necesito pensar se duerme, no resiste más suelo que la calle, sólo cuando lo saco de noche revive, cuando lo llevo a gozar banalmente, mi cuerpo es el síntoma de esta ciudad, me traiciona $[\ldots]$

Afuera daba vueltas un farol rojo y el letrero se caía a pedazos como de boite de mala muerte, como si fuésemos a estrellarnos contra la muerte. (Urriola22-23)

En esta construcción urbana de "políticas de las memorias" se encuentran, por ejemplo, los habitantes del barrio, del callejón, del pasaje, del pueblo, del patio, etc.; pero también el sujeto que, en su propia -y ajena- soledad, elabora discursos de subjetivación entre medio de una ciudad más amplia y degradada. Una ciudad cercana a la prostitución, como simbólica potente de la cosificación del cuerpo por los poderes del mercado y del patriarcado:

Llueve luminoso en la metrópoli: una mujer japonesa cruza el cielo, el violinista más hermoso del mundo toca en Times Square, pan am, grafittis, los hermanos Taviani están copiando al gran Fellini, razas, lenguas, el Bronx parece Beirut. Luz, cámara: la confusión es completa, los ángeles se prostituyen en los muelles. (Negroni 19).

Un escenario urbano próximo o más bien producido a partir de lo que Benjamin llama "fantasmagoría" de la ciudad capitalista moderna, es decir, el espacio citadino en donde el sujeto se adentra para dejarse 
desperdiciar, abandonándose a las manipulaciones de esta ciudad -convertida en mercancía- y en la cual va a complacerse de la enajenación de sí mismo y de los demás (Benjamin, 1998). ${ }^{14}$

El micro entorno urbano del sujeto cotidiano es apropiado como lugar de experiencias, las que se identifican como territorios de memoria que posibilitan la producción de una subjetividad específica que le adscribe significados muy distintos a los asignados por la memoria oficial. Esta última, es un contrato geográfico urbano dominante que ha ido devorando, desde las dictaduras en adelante, los trayectos por la ciudad y el movimiento que ese mismo desplazamiento produce en el sujeto a través de las calles, los barrios, las plazas, las avenidas, etc. De esta forma, logra instalar en el lugar del movimiento y la subjetividad la ansiedad de un consumidor desaforado y encerrado que da vueltas en círculos dirigidos dentro de un supermercado o de un mall. La asepsia y homogeneidad de los espacios ${ }^{15}$ ha tenido como consecuencia, por una parte, la desertificación de la ciudad actual y, por otra, la transformación del espacio urbano en puro paisaje artificial: "Calles anchas sin árboles, peatones, perspectivas, dibujos en damero, campo visual" (Negroni 56). Sin embargo, la esterilización y uniformidad de la ciudad oficial inevitablemente se "contamina", y esto es lo que aparece con énfasis en la poética de la época,con sujetos que si bien no están exactamente fuera de estos intramuros -porque nunca se está totalmente fuera del sistema-, sí son conscientes de su precariedad, de su marginalidad y de su diferencialidad en relación a esta ciudad nacional. Por lo tanto, lo que abren estos textos es siempre el camino a la problemática de la identidad:

Este pequeño nombre

singular, femenino, no me sienta

me queda un poco estrecho y ya gastado.

A ver -nos pide- si se lo cambiamos

un poco, al menos,

14 Para Benjamin, en la ciudad capitalista la mercancía se transforma en "la quintaescencia de la conciencia falsa cuyo incansable agente es la moda. Este halo de lo nuevo se refleja, tal un espejo en otro, en el halo de los siempre-otra-vez-igual. El producto de esta reflexión es la fantasmagoría de la 'historia de la cultura' en que la burguesía paladea su falsa conciencia" (Benjamin, Poesía y capitalismo 186).

15 Ejemplo de esto es la masiva construcción, desde los 80 en adelante, de mega centros comerciales cerrados que absorben la mirada hacia los intramuros de la ciudad de la mercancía, reproduciendo un orden disciplinador heredado de la cuadratura de la ciudad colonial. 
para que pueda verse por la calle

no desentonar con el asfalto (Maia305)

[...]

Todos tenemos domicilios

particulares, propios. Cierra la puerta.

Así está mejor; pequeño círculo.

Bueno, círculo no, hay ángulos: un cuarto,

paredes protectoras, techo y piso sólidos. (Maia 319) ${ }^{16}$

Aun cuando en los poemas pueda recuperarsela gran ciudad, la mayor parte de los textos siguen posicionando una memoria local de identidades, las que realizan recorridos microgeográficos que se corresponden con las micromemorias. Esto, no a modo de una operación identitaria resuelta individualmente, sino que más bien se trata de como "microbiográficas" que se emplazan como subjetividades políticas del territorio. En este sentido, los poemarios hacen presente las distintas realidades urbanas: sociales, de género, de represión, de "fantasmagorías", entre otras y, ante lo cual, las escrituras potencian trayectos marginales de revuelta que le hacen frente a una ciudad ocupada por los poderes hegemónicos:

Tu último camino

Recorrido por callejones

Callampas y zanjones

Injundias

Prostíbulos y comadronas

[...]

Y qué camino

Ramera

Masticando el orgullo

Milonguera flor de noche

16 Ambos fragmentos, pertenecen al libro Superficies publicado en 1990 en Montevideo por Ediciones de la Feria. 
Matadero frugal

Al matadero

Esquelética de fierros

Bofe colgando de los sueños

Rociada de flores

En avenida La Paz

Por el pelusa miguel

Volado

Escupiendo coágulos. (Berenguer 38)

Las memorias locales de la ciudad, tienen presente que la experiencia urbana finisecular está filtrada por anomalías temporales y espaciales que surgen de los sentidos de pérdida, de cortes, de exclusiones, de olvidos y de violencias; pero también, de las nuevas experiencias y de los nuevos sujetos que se construyen a partir de las mismas excavaciones en las memorias locales.

\section{Conclusiones preliminares}

Sin duda queen esta relación descriptiva de producciones urbanas que acabamos de esbozar, existe un abanico más amplio en las posibilidades de posicionamiento de la ciudad. No olvidemos, finalmente, que la ciudad se diseña como un dispositivo de ordenamiento social, o sea, de disciplinamiento de cuerpos, subjetividades e identidades a partir de una organización anglo, euro y androcéntrica. Se trata de un sistema de signos que regulan el comportamiento social en beneficio de un poder central que preconcibe las "demás" identidades como una variación de sí mismo o como objetos diferentes a su "norma", por lo que deben ser regulados.

De modo similar a como se estructura el lenguaje simbólico, el ordenamiento de la ciudad omite, oculta o reprime otras marcas urbanas que han quedado subsumidas o generalizadas dentro de un modelo de ciudad oficial. Como sabemos, el lenguaje es un sistema que representa las realidades social, cultural e ideológica a la vez que las produce. Sin embargo, al indagar en cómo esta univocidad lingüística 
interpreta estas realidades, podemos ver que tras ellas existe una pluralidad de enunciaciones etarias, de género, de raza y de clase que promueven subjetividades diferenciadas. Desde la perspectiva de que la construcción urbana también es un sistema de signos que produce y administra subjetividades, el establecimiento de la ciudad como enunciación fija de un poder central puede quedar al descubierto en la medida que las identidades censuradas hagan su aparición como microterritorios de resistencia, denuncia y reivindicación. Por lo tanto y tal como se planteó al inicio de este artículo, la representación del espacio urbano reprimido va a tender a la rebeldía y a la emergencia de sus posibilidades diferenciales.

Es a través de fisuras latentes y reales de la ciudad institucional, que se manifiestan cuerpos, subjetividades, memorias, afectos, desafectos y otras circulaciones de la alteridad que ocupan y usan un lugar ya sea marginal, del entre medio, de la frontera, periférico o como se le quiera llamar a la experiencia y apropiación local y política del cuerpo sobre el espacio. Nos referimos aquí al tener un lugar, usarlo y dar cuenta de él -por más precario que este sea-, tanto a nivel material como a nivel de las representaciones literarias, como es en nuestro caso. Sin embargo, también es relevante preguntarse por quién tiene, usa y da cuenta de esta parcialidad urbana, porque aquí entran en juego diversas dinámicas identitarias del género y de las experiencias de la diferenciación y además, porque se trata de sujetos históricos -no tan solo temporales como ha querido enseñarnos la tradición historiográfica-, sino que con un vínculo singular a un espacio también histórico.

De aquí, entonces, que no alcancemos a explorar otras formas de producir identidades urbanas en los poemarios, puesto que sería un trabajo mayor. Sin embargo, al menos podemos mencionar algunas otras apropiaciones cartográficas que podrían estar en las poéticas revisadas: "ciudad invisible" (Ítalo Calvino), "ciudad perversa" (cercana a la ciudad pánico), "ciudad nómada", "ciudad ausente", "ciudad apocalíptica" (Lucía Guerra), "ciudad en ruinas", (Betuel Bonilla, Circe Maia), "ciudad mediática", "la puta ciudad" (Fito Páez), "ciudad anárquica" (Alexis Candia), "mapurbe", "mierdópolis" y "santiagóniko" (David Aniñir), "ciudad quiltra" (Magda Sepúlveda), "ciudad ajena" (Lucía Guerra), "ciudad anal" (Pedro Lemebel), "Maldivia", "Coyhaiqueer" y "Patriagonia" (Ivonne Coñuecar) y otras políticas locales como la 
comarca mapuche, el barrio, la calle, la población, la avenida, la casa, la animita, entre otras, que también son parte de un imaginario urbano.

Es así como esta cartografía de espacios diversos, que al mismo tiempo es una cartografía de tiempos diversos, remueve cualquier intento funcional de un solo centro aglutinador. La poesía finisecular de mujeres en el Conosur, al igual que otras prácticas poéticas, pone en circulación dentro de la ciudad oficial un flujo de desorganización y diseminación que da cuenta de una experiencia urbana mucho más amplia y compleja. Esta porosidad heterogénea de la ciudad, ya anunciada por Benjamin en sus reflexiones sobre la ciudad, plantea la imposibilidad de escribir o imaginar la ciudad total, a la vez que impugna, tal como lo afirma Lucía Guerra:

[...] la posibilidad de cualquier desciframiento unívoco $\mathrm{y}$ totalizante de la ciudad, por ser un espacio fluido $\mathrm{y}$ multiforme donde transita lo fugaz y huidizo [...]. Esta porosidad, en una pluralidad de elementos heterogéneos y dispares, impide cualquier interpretación o análisis sistemático de la ciudad. (Ciudad, género e imaginarios...19)

En este sentido,y para concluir estos comentarios finales, hay dos cosas que ya se han dicho, y que van de la mano, que me gustaría subrayar. Una es que el proyecto urbano es la estructura fundante y continuaexcepto cuando los mapuches quemaban las ciudades establecidas por los españoles, lo que además, deriva en la política de otra ciudad: "la ciudad en llamas"-, para la transmisión y propagación de poderes políticos y económicos que regulan las identidades. Y la segunda es que, a pesar de lo anterior, o paradojalmente, la ciudad en América Latina, como ya decíamos en las páginas iniciales, no ha sido una construcción indivisa, ya que constantemente ha sido asediada por los "bárbaros" y las "bárbaras", quienes complejizan el tránsito urbano poniendo en circulación trayectos mínimos, subversivos, fugaces, imprevistos, clandestinos, desviados y enmascarados. Y es aquí donde la poesía entra con sus diferentes sentidos para visibilizar subjetividades "bárbaras" expuestas o producto de la violencia de los poderes de la ciudad oficial. De este modo, las variadas resignificaciones de la ciudad en la poesía de mujeres del Conosur durante las dictaduras y la primera postdictadura se comprenden como un campo cultural y de producción de políticas de la subjetividad que promueve diversos discursos que intervienen el 
orden hegemónico dela ciudad, posicionándose en las intrahistorias de sujetos cotidianos.

En los poemarios se procesan imaginarios que rastrean márgenes y flujos rebeldes de la ciudad a partir de una metafórica urbana diversa queno está sola. La acompañan significaciones del género, de la memoria, del afecto, de la nación y de la violencia entre otras como los contextos militares y de libre mercado. Todas estas dimensiones de los discursos poéticos son entendidas en este estudio como un tejido de sentidos de la historia, de la sociedad, de la cultura y de las identidades que vienen a ampliar la comprensión de la poesía de la región. Finalmente, considero que esta producción literaria constituye, hoy día, un corpus y un repertorio poético histórico importante que goza de un gran potencial de subjetividades y experiencias de cambio social y cultural,no solo en el Conosur, sino que también en América Latina. 


\section{Referencias Bibliográficas}

Benjamin, Walter. Poesía y capitalismo. Madrid: Taurus, 1998 . Escritos autobiográficos. Madrid: Alianza Editorial, 1996.

Berenguer, Carmen. Huellas de siglo. Santiago de Chile: Editorial sin Fronteras, 1986.

Déotte, Jean-Louis. La ciudad porosa. Walter Benjamin y la arquitectura. Santiago de Chile: Ediciones Metales pesados, 2013.

Fondebrider, Jorge. Una antología de la poesía argentina (1970-2008). Santiago de Chile: Lom Ediciones, 2008.

Franco, Graciela, González, María del Carmen y Núñez, Patricia, Eds. Obra poética. Circe Maia. Montevideo: Rebeca Linke Editoras, 2015.

Guerra, Lucía. La ciudad ajena. Subjetividades de origen mapuche en el espacio urbano. Santiago de Chile: Ceibo Ediciones, 2014. . Ciudad, género e imaginarios urbanos en la narrativa latinoamericana. Santiago de Chile: Cuarto Propio, 2014.

Guerra, Silvia, Edit. el velo magistral que esconde todo. nancy bacelo. Montevideo: Fundación Nancy Bacelo, 2011.

Hernández, Elvira. La Bandera de Chile. Buenos Aires: Libros de Tierra Firme, 1991.

Kamenzain, Tamara. "Tango Bar." Una antología de la poesía argentina (1970-2008). Comp. Jorge Fondebrider. Santiago de Chile: Lom Ediciones, 2008.

Lukin, Liliana. Descomposición. Buenos Aires: Ediciones de la Flor, 1986.

Maia, Circe. Obra poética. Montevideo: Rebeca Linke Editora, 2015.

Makowski, Sara. "Reseñas: Patricia RAMÍREZ KURI, y Miguel Ángel AGUILAR DÍAZ, coords., Pensar y habitar la ciudad: afectividad, memoria y significado en el espacio urbano contemporáneo." Revista Mexicana de Sociología2.69(2007): 373-386. 
Medrano, María. “Visita”. Poetas argentinas (1961-1980). Selección y prólogo Andi Nachón. Buenos Aires: Ediciones del Dock, 2007.

Mignolo, Walter. "La semiosis colonial: la dialéctica entre representaciones fracturadas y hermenéuticas pluritópicas". Adversus. Revista de Semiótica 3(año II). Web. 2005.

Muñoz, Boris y Spitta, Sylvia (edit), Más allá de la ciudad letrada: Crónicas y espacios urbanos, Pittsburgh: Biblioteca de América, 2003.

Nachón, Andi. Poetas argentinas (1961-1980). Buenos Aires: Ediciones del Dock, 2007.

Negroni, María. La jaula bajo el trapo. Santiago de Chile: Cuarto Propio, 1999.

Puppo, María Lucía. Entre el vértigo y la ruina. Poesía contemporánea y experiencia urbana. Buenos Aires: Editorial Biblos, 2013.

Spitta, Silvia. "Prefacio. Más allá de la ciudad letrada". Más allá de la ciudad letrada: Crónicas y espacios urbanos. Eds. Boris Muñoz y Silvia Spitta. Pittsburgh: Biblioteca de América, 2003. 7-23.

Urriola, Malú. Hija de perra. Santiago de Chile: Surada Ediciones, 2002.

Virilo, Paul. Ciudad pánico. El afuera comienza aquí. Caracas: Monte Ávila Editores Latinoamericanos, 2008. 